\title{
Metro Route Site Selection for Madurai City Using Remote Sensing and GIS
}

\author{
Elangovan k \\ \{ ela.civil@psgtech.ac.in\} \\ Professor, Department of Civil Engineering, PSG College of Technology, Coimbatore,india.
}

\begin{abstract}
This study mainly deals with the selection of optimal locations for metro network and stations in Madurai city as a solution to meet the present and future transportation demands. Remote Sensing, Geographic Information System and AHP have been used for the purpose of extracting data, pre-processing, prioritizing and analyzing the data spatially. For the site selection process, criteria like population density, important locations that attracts traffic, busy intersections, existing road networks, land use - land cover and slope maps are considered. Each criteria map is ranked according to its suitability and weightage to each criteria is obtained by Analytical Hierarchical Process based on their relative importance to the selection process. Weighted overlay analysis is carried out using GIS by superimposing all the weighted criteria maps. As a result, four routes are selected as decision alternatives with four end stations (origin and destination stations) - two routes in south west to north east direction and two routes in east to west direction and intermediate stations are identified along the selected routes. Finally two routes (one in each direction) are proposed as optimal metro routes. The proposed metro lines can be extended to places that will be densely populated in future.
\end{abstract}

Keywords: Metro route selection; GIS; Madurai; Site selection; AHP; Spatial analysis.

\section{Introduction}

Increase in vehicular traffic in Madurai city results in traffic congestion, air pollution and increased the number of road accidents. This has led to a demand for an alternative mass transportation system which is more effective, fast and reliable than the existing road transportation facilities. Proposing a mass transit system is therefore necessary to meet the present transport demand and also to reduce the negative impacts of existing road transportation systems. Metro system is an electrically operated means of transport which operates on an exclusive right of way with protected at-grade crossing and has a capacity to carry more than 1500 passengers per train (Shafik Jendia and Mohammed Skaikm, 2016). A metro rail consists of minimum three number of coaches and depending upon the requirement it can be increased to eight. Metro systems are mostly operated in inner metropolitan areas of cities having high population density (Maher A. EI-Hallaq and Khalid D. EI- Yazory 2017). The primary goal of the site selection process is to find the optimal locations for metro network and stations that meet predefined selection criteria. Such a process involves manipulation of spatial data and requires fulfillment of multiple criteria to take critical and successful decisions. Geographic Information System (GIS) has been widely used in the field of transportation to take critical decisions in planning, modelling, transit service planning and accident analysis due its ability to manage, store, manipulate, analyze, retrieve and visualize 
the geographical information (Elangovan,2006, Andras Farkas, 2009). But GIS will not deal with multiple decision factors. For the purpose of handling multiple decision parameters, Multi Criteria Decision Making (MCDM) method has to be used (Srimathi et 2014, Rajkumar and Elangovan,2020). Hence this study employs both Geographic Information System to manage spatial and non-spatial data, to perform suitability analysis and MCDM System, usually the Analytical Hierarchical Process (AHP) for prioritizing the criteria based on their importance.

\section{Study area}

Madurai city is located in southern side of Tamil Nadu, spans between $78^{\circ} 2{ }^{\prime} 43^{\prime \prime}$ and $78^{\circ} 11^{\prime} 8^{\prime \prime} \mathrm{E}$ and $9^{\circ} 50^{\prime} 18^{\prime \prime}$ and $9^{\circ} 59^{\prime} 40^{\prime \prime} \mathrm{N}$. It is considered as the third largest city of the state and has got 25 th position in India in terms of population. The city is located at an elevation of about 101 meters and the corporation boundary covers an area of $147.97 \mathrm{~km}^{2}$. As per 2011 census the population of Madurai metropolitan region is 1.47 million and it is estimated that, the population exceeds 3 million in the year 2019. Madurai city boundary is divided into 100 wards and the ward map of the city is shown in Fig. 1.

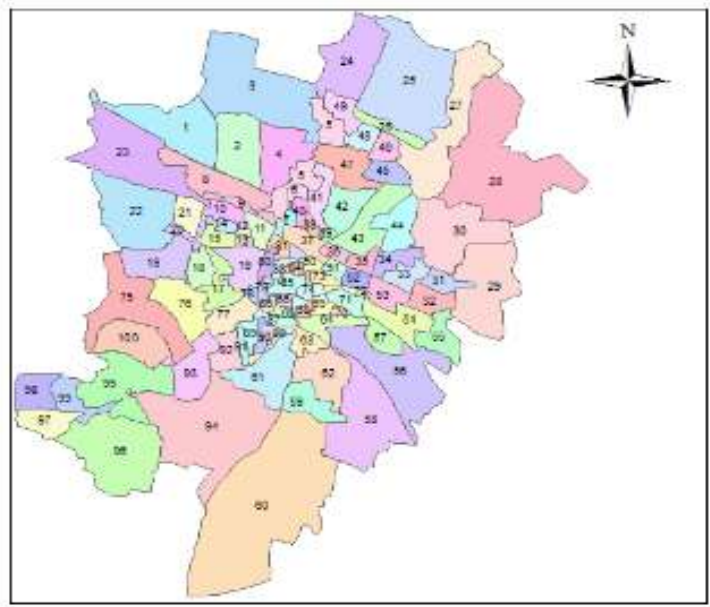

Fig. 1. Ward map of study area.

\section{Methodology}

The criteria required for the site selection process have been identified. Required data are collected from relevant sources and pre-processed in order to convert the data into GIS acceptable formats. Pre-processing involves digitizing the base map, adding attribute data, geo-referencing etc. Then each criteria map is ranked such that the area which is more suitable for the site selection will get the highest rank. Prioritization of criteria is done by Analytical Hierarchy Process (AHP), considering the relative importance of criteria for site selection. Final composite map which shows the optimal locations for metro network is obtained by 
Weighted Overlay Analysis by overlapping all the weighted criteria maps. After finding the suitable locations for end stations, least cost paths (decision alternatives) connecting the end stations are obtained and the intermediate stations are distributed along the selected rail routes. From the decision alternatives, optimal routes are selected by calculating the effectiveness of each route based on the extent to which the stations located along a particular route is suitable for metro network.

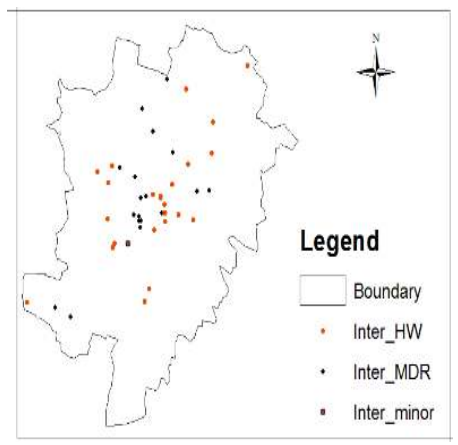

\section{Data collection and pre-processing}

Data required for the suitability analysis are picked out from the predefined criteria and collected from relevant sources. The data collected include the following - ward wise population, important places, existing road network, busy intersections, slope, and landuse/land-cover.

\subsection{Population density}

Ward wise population for the past three decades are collected from Madurai Corporation and projected for the year 2041 by appropriate forecasting methods based on the growth trend. The projected population is added to the digitized ward map as attribute data. Then the population density map is generated by normalizing the projected population of each ward by their corresponding area and the map is converted to raster format. The maps are shown in the Fig. 2.

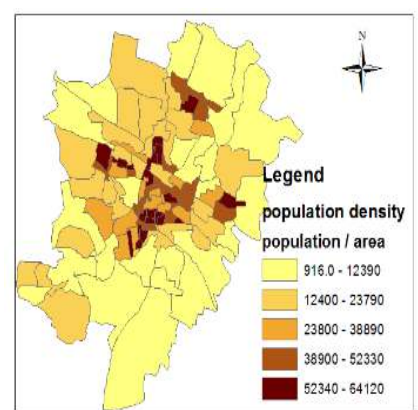

(a)

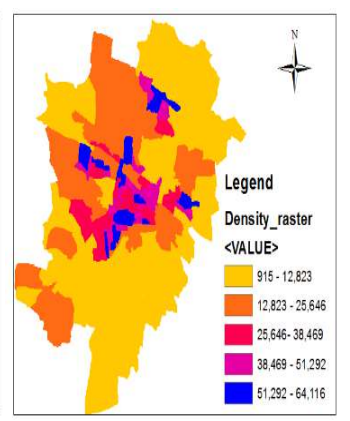

(b)

Fig.2. (a) Population density map; (b) Density map in raster. 


\subsection{Important locations}

Important locations which attract people from various places like bus stops, educational institutions, offices, hospitals etc.., are identified and digitized which is shown in Fig 3 a. The map which is in vector format is converted to raster so that the map can be ranked. Hence a buffer of $500 \mathrm{~m}$ is created around bus stops and a buffer $1000 \mathrm{~m}$ is created around all other location and is shown in Fig. 3 b.

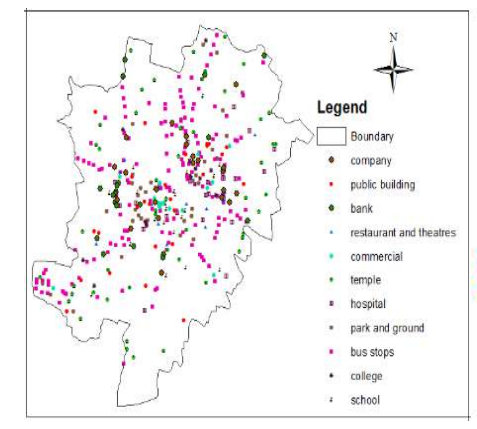

(a)

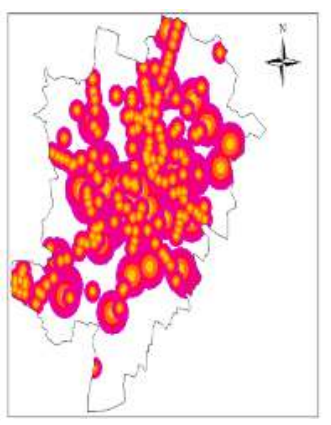

(b)

Fig. 3. (a) Important locations; (b) Locations with buffer.

\subsection{Intersections}

Forty five major intersection have been identified based on the traffic count and its proximity to important places. The traffic details are obtained from Comprehensive Mobility Plan report of Madurai city. Around each intersection a buffer of $500 \mathrm{~m}$ is created.

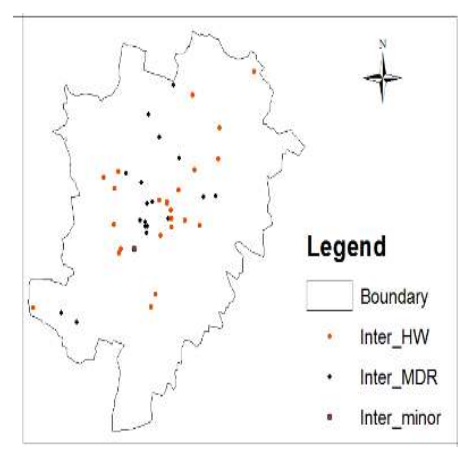

(a)

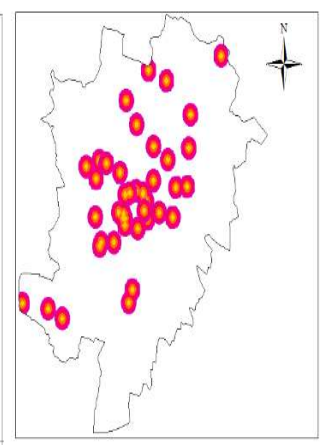

(b)

Fig.4. (a) Intersections; (b) Intersections with buffer.

\subsection{Road networks}

All the existing road networks in Madurai city including highways, major district roads and other minor networks are digitized. A buffer of $500 \mathrm{~m}$ is created on either sides of all the 
road networks to rank the map for spatial analysis. The digitized map and buffer zones are shown in Fig. 5.

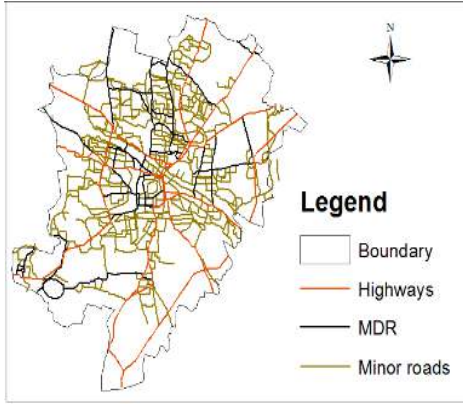

(a)

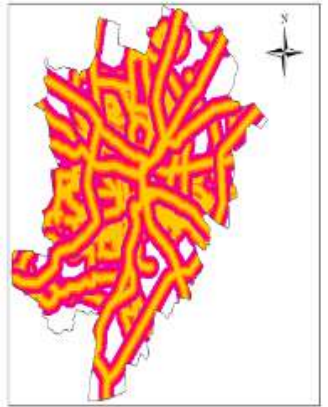

(b)

Fig. 5. (a) Road networks; (b) Road networks with buffer.

\subsection{Slope}

The slope map of the study area is derived from DEM data using slope spatial analyst tool available in GIS which is shown in Fig. 6. The DEM data is obtained from Advanced Space borne Thermal Emission and Reflection Radiometer Global Digital Elevation Model (ASTER GDEM).

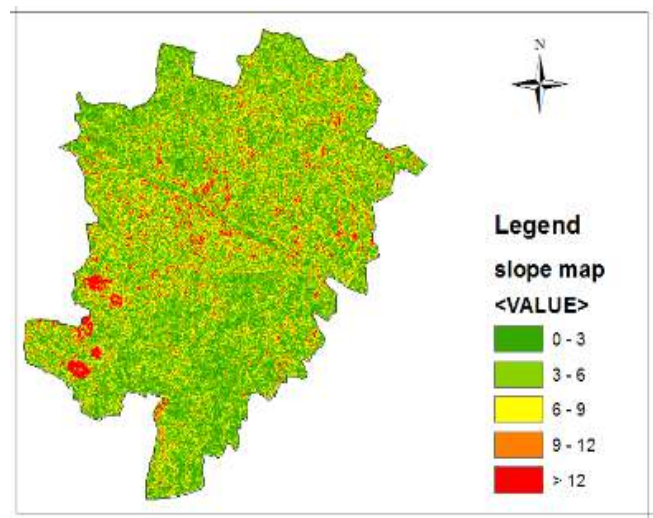

Fig. 6. Slope map.

\subsection{Land use - Land cover}

The land use - land cover map shown in Fig. 7 is derived from Landsat 8 satellite imageries. Supervised classification method is adopted in order to identify the surface features. Madurai city is found to have different surface features including agricultural area, urban settlement, fallow land and water bodies. From the Fig.7, it is observed that most of the areas in the city are occupied by human settlement. 


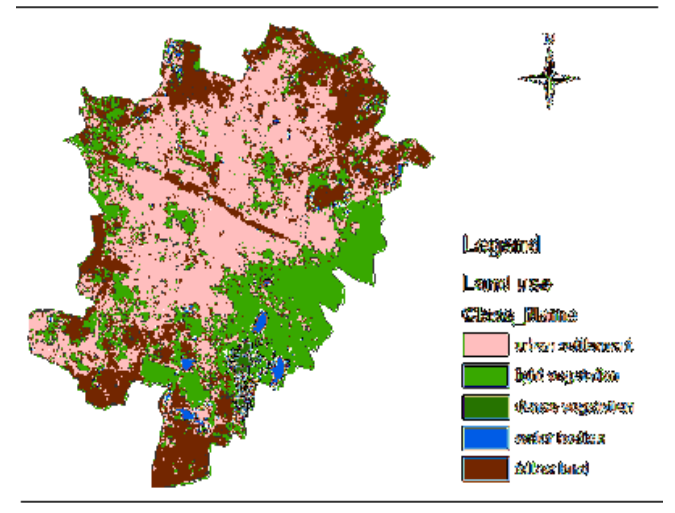

Fig. 7. Land use map.

\section{Re-classification of criteria map}

Each criteria map is reclassified according to its suitability. The scale adopted to reclassify the map is shown in Table 1.

Table 1: scale adopted for ranking the criteria

\begin{tabular}{|l|l|l|l|l|l|}
\hline Rank & 1 & 2 & 3 & 4 & 5 \\
\hline Suitability & $\begin{array}{l}\text { Very } \\
\text { low }\end{array}$ & Low & Moderate & High & $\begin{array}{l}\text { Very } \\
\text { high }\end{array}$ \\
\hline
\end{tabular}

1. Population density: The population density map is ranked in such a way that the areas having highest population density get the highest rank and areas with least density value get the lowest rank. The ranking adopted is shown in Table 2.

Table 2: Ranking of density map

\begin{tabular}{|l|l|}
\hline $\begin{array}{l}\text { Population density } \\
\left(\text { per } \mathrm{km}^{2}\right)\end{array}$ & Rank \\
\hline $915-12823$ & 1 \\
\hline $12823-25646$ & 2 \\
\hline $25646-38469$ & 3 \\
\hline $38369-50292$ & 4 \\
\hline$>50292$ & 5 \\
\hline
\end{tabular}

2. Important locations: Here the ranking is based on the proximity of the buffer zone to important places. The area which is close to the locations will get highest rank and the rank will get decreased as the distance from the location increases as shown in Table 3. 
Table 3: Ranking of locations

\begin{tabular}{|l|l|}
\hline Distance $(\mathrm{m})$ & Rank \\
\hline$>1000$ & 1 \\
\hline $750-1000$ & 2 \\
\hline $500-750$ & 3 \\
\hline $250-500$ & 4 \\
\hline $0-250$ & 5 \\
\hline
\end{tabular}

As each location will attract traffic in different proportion according to its importance, the weightage to each location is found by AHP and by performing weighted overlay analysis a composite map for locations is obtained. Similarly the composite map for intersections and road networks are obtained by adopting the same ranking as locations.

3. Slope map: Flat areas are more suitable for construction as it is more economical. Hence the area with least slope will get the highest rank and maximum slope will get the lowest rank. Table 4 shows the rank of the slope value.

Table 4: Ranking of slope values

\begin{tabular}{|l|l|}
\hline Slope (degree) & Rank \\
\hline$>12$ & 1 \\
\hline $9-12$ & 2 \\
\hline $6-9$ & 3 \\
\hline $3-6$ & 4 \\
\hline $0-3$ & 5 \\
\hline
\end{tabular}

4. The ranking adopted for Land use classification is shown in the Table 5.

Table 5: Ranking of land use

\begin{tabular}{|l|l|}
\hline Land use & Rank \\
\hline Water bodies & 1 \\
\hline Urban settlement & 2 \\
\hline Dense vegetation & 3 \\
\hline Light vegetation & 4 \\
\hline Bare ground & 5 \\
\hline
\end{tabular}

Weighted evaluation criteria

To create a final composite map, each criteria is prioritized by considering its importance to the suitability analysis. The weightage to all the predefined criteria are calculated by Analytical Hierarchy Process (Saaty's method). Initially a pairwise comparison matrix is generated by making appropriate judgments and after obtaining the weightage to criteria, a consistency check is carried out to check the accuracy of the judgments made. The sum of all the weightage values must be equal to 100 . The composite suitability score of all the raster 
cells are calculated to obtain the final suitability map which merges all the ranked criteria maps by weighted overlay analysis using GIS.

Table 6: criteria weightage

\begin{tabular}{|l|l|}
\hline Criteria & Weight (\%) \\
\hline Population density & 34 \\
\hline Important places & 30 \\
\hline Intersections & 15 \\
\hline Road networks & 10 \\
\hline slope & 6 \\
\hline Land use-Land cover & 5 \\
\hline Total & 100 \\
\hline
\end{tabular}

From the spatial analysis carried out in GIS, the final suitability map obtained is shown in the Fig. 8 the area shown in red color (rank 4) is the most suitable area and the area in dark green color (rank 1 ) is the least suitable area for metro network.

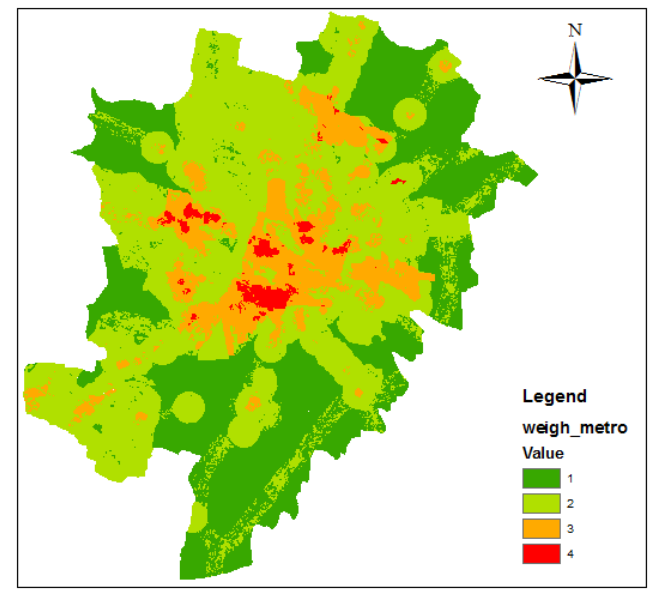

Fig. 8. Final composite map.

\section{Selection of optimal metro routes}

Initially the end stations for the metro network are fixed such that the proposed metro route will cover all the interlaying suitable locations. Then by using least cost path tool, the metro network is drawn between the origin and destination stations. Intermediate metro stations are distributed along the selected metro lines (decision alternatives). Four routes are fixed as decision alternatives as shown in Fig. 9. Route 1 and 2 have same origin and destination. Similarly the origin and destination stations for Route 3 and 4 are same. So one route in each direction should be chosen. The impedance value of each route is calculated. The route with minimum impedance value is fixed as optimal route. The impedance value calculations for decision alternatives are shown in the Table 7. 
Mean Spatial Utility:

$\mathrm{MSU}_{i}=\sum_{j=1}^{N} \mathrm{U}_{j} / \mathrm{N}, \quad i=1,2, \ldots \mathrm{M}$

Impedance:

$\Omega_{i}=\left(5-\mathrm{MSU}_{i}\right) * \mathrm{~L}_{i}, \quad i=1,2, \ldots \mathrm{M}$

Optimal value: $\quad \Omega^{*}=\min \left\{\Omega_{i}\right\}$

$\mathrm{L} i$ - length of $i$ th route

$\mathrm{U} j$ - suitability index of the pixel underlying the $j$ th metro station along $i$ th route

$\mathrm{M}$ - No. of alternative routes

$\mathrm{N}-$ No. of selected stations along the $i$ th route

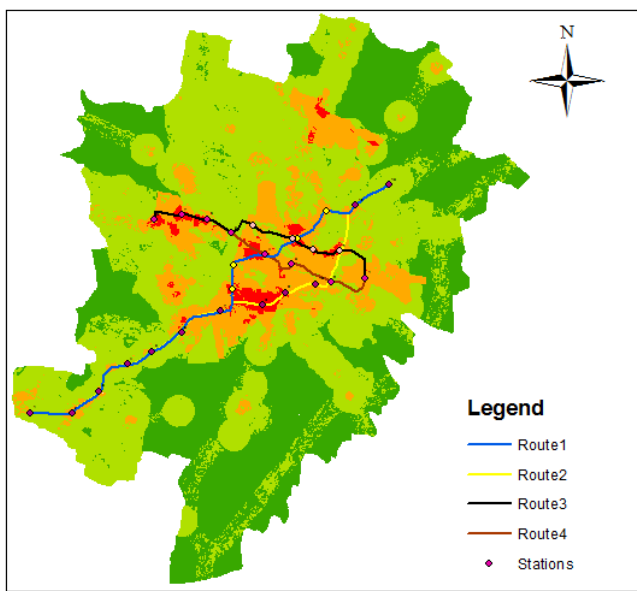

Fig. 9. Decision alternatives.

Table 7: Impedance values

\begin{tabular}{|l|l|l|l|l|}
\hline Direction & \multicolumn{2}{|l|}{ SW - NE } & \multicolumn{2}{l|}{ E-W } \\
\hline Route & Route 1 & Route 2 & Route 3 & Route 4 \\
\hline No. of stations & 14 & 13 & 9 & 8 \\
\hline Length (km) & 14.816 & 14.791 & 8.069 & 7.8 \\
\hline MSU & 3.357 & 2.975 & 3.966 & 3.462 \\
\hline \multicolumn{1}{|c|}{$\Omega_{i}$} & 24.343 & 29.952 & 8.343 & 11.996 \\
\hline$\Omega^{*}$ & 24.343 & & 8.343 & \\
\hline Optimal route & Route 1 & Route 3 & \\
\hline
\end{tabular}


From the four alternative routes, Route 1 and Route 3 which has the minimum impedance value compared to Route 2 and Route 4 respectively are fixed as best optimal metro networks. The proposed optimal metro lines are shown in the Fig. 10 and the list of metro stations are shown in the Table 8.

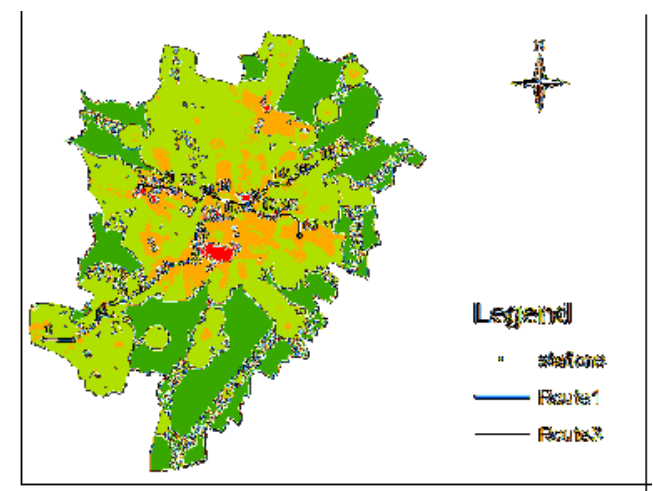

Fig. 10. Optimal metro routes.

Table 8: List of metro stations

\begin{tabular}{|c|c|c|c|}
\hline Route & Station no. & Station name & Distance between stations $(\mathrm{km})$ \\
\hline \multirow{14}{*}{ Route 1} & 1 & Thirunagar & 1.279 \\
\hline & 2 & Tiruparankunram & 1.089 \\
\hline & 3 & Thyagaraja college & 1.384 \\
\hline & 4 & Pasumalai & 0.879 \\
\hline & 5 & Pykara & 1.074 \\
\hline & 6 & Palanganatham & 1.481 \\
\hline & 7 & Madura College & 0.940 \\
\hline & 8 & Periyar & 0.783 \\
\hline & 9 & Madurai Junction & 1.220 \\
\hline & 10 & Simmakkal & 1.243 \\
\hline & 11 & Gorippalayam & 1.216 \\
\hline & 12 & Outpost & 1.023 \\
\hline & 13 & K K Nagar & 1.205 \\
\hline & 14 & Matuthavani & \\
\hline \multirow{6}{*}{ Route 3} & 15 & Anna Nagar & 1.523 \\
\hline & 16 & Anna Bus Stand & 0.849 \\
\hline & 17 & Medical College & 0.716 \\
\hline & 11 & Gorippalayam & 1.293 \\
\hline & 18 & Sellur & 0.890 \\
\hline & 19 & Arapalayam cross road & 0.853 \\
\hline
\end{tabular}




\begin{tabular}{|l|l|l|l|}
\hline & 20 & Arapalayam & 0.861 \\
\cline { 2 - 4 } & 21 & Guru Theater & 1.084 \\
\cline { 2 - 4 } & 22 & Bethaniyapuram & \\
\hline \multicolumn{2}{|l|}{} \\
\hline
\end{tabular}

\section{Conclusion}

Six parameters have been identified to select the best locations for metro network population density, existing road networks, important locations, busy intersections, land-use, and slope. All the ranked criteria maps are prioritized by Analytical Hierarchy Process. By using weighted overlay analysis in GIS, four routes were selected as decision alternatives. And the best optimal network is selected by measuring the effectiveness of the selected metro lines. Impedance value of each route is calculated and the routes having minimum impedance are fixed as the optimal routes. Finally two metro lines (Route 1 and Route 3) have been selected as best optimal routes. Route 1 - covers a length of $14.816 \mathrm{Km}$ and passes through 14 metro stations. Route 3 - covers a length of $8.343 \mathrm{Km}$ and passes through 9 metro stations. The total length of the proposed metro network is $22.885 \mathrm{~km}$ and consists of 22 metro stations (1 common junction) including four end stations. The total approximate cost required for the construction of the metro network is 2980 crores. The proposed routes can be further extended to reach places that will be densely populated in future.

\section{Acknowledgement}

The authors wish to thank Dr. R. Rudramoorthy, the Principal, Dr. G. Sankarasubramanian, the Head of the Department of Civil Engineering, PSG College of Technology for providing the necessary facilities and guidance to complete the work successfully.

\section{References}

[1] Andras Farkas, 2009. "Route/site selection of urban transportation facilities: An integrated GIS/MCDM approach", International Conference on Management, Enterprise and Benchmarking, volume 1, pages 169-184..

[2] Ibrahim A. Hammadi., Saleh Mesbah, and Khaled Mahar, 2008. "Transportation network design using GIS based DSS: Baghdad metro case study", selected papers from the WSEAS Conferences in Istanbul, vol. 1, pages 17-25.

[3] Elangovan. K, (2006). " GIS Fundamentals, Applications and Implementations ”, New India Publishing ,New Delhi.

[4] Maher A. EI-Hallaq and Khalid D. EI- Yazory, (2017). “ Metro route site selection in Gaza city using GIS and Spatial Multi Criteria Evaluation”, International Journal of Engineering Inventions, volume 6 , pages 11-21.

[5] Mustafa Hamurcu and Tamer Eren, (2016). “ A Multi Criteria Decision-Making for Monorail route selection in Ankara ", proceedings of AWIC, volume 1, pages 6-10.

[6] Namir Ghani Ahmed and Noor Moutaz Asmael, (2015). "A GIS-Assisted optimal Baghdad Metro route selection based on Multi Criteria Decision Making ", Journal Of Engineering And Development, volume 19, pages 44 -58. 
[7] Rajkumar R and Elangovan K, 2020, Impact of urbanisation on formation of urban heat island in Tirupur egion using geospatial technique, Volume 49, Issue 9, Pages 1593 - 1598

[8] Shafik Jendia and Mohammed Skaikm, (2016). "Gaza Metro network - Route site selection ", Journal Of Engineering Research And Technology", volume 3. Pages 6-15

[9] Srimathi N, Sathishkumar V and Elangovan K, 2014, "Land Use Land Cover Change Detection using Remotely Sensed Data for Coimbatore City", International Journal of Earth Sciences and Engineering, Vol. 7, No. 2, pp. 624-631

[10] Subash. S.M, Chandrabose. K, Umamaheshwari. U, and Maharajan. T., (2013). "Feasibility study on metro transport: case study Madurai ", International Journal of Civil Engineering and Technology, volume 4, pages 72-83.

[11] Vimal Gahlot, Swami. B.L, Jain. S.S and Parida. M, (2011). "Planning of MRTS for metro cities on GIS platform ", Journal Of Engineering And Development, volume 1, pages 9-13.

[12] M. Tholkapiyan, A.Mohan, Vijayan.D.S , "A survey of recent studieson chlorophyll variation in Indian coastal waters", IOP Conf. Series: Materials Science and Engineering 993 (2020) 012041, doi:10.1088/1757-899X/993/1/012041.

[13] S. M. S. S, D. S. Vijayan, M. Anand, M. Ajona, and T. Jarin, " Biodegradation of P-nitro phenol using a novel bacterium Achromobacter denitrifacians isolated from industrial effluent water ," Water Sci. Technol., vol. 00, no. 0, pp. 1-12, 2021, doi: 10.2166/wst.2021.354. 